\title{
artigo
}

\section{Atenção à saúde do trabalhador na vigilância ao COVID-19: um relato de experiência}

\author{
Attention to workers' health in the surveillance of COVID-19: an experience report \\ Atención a la salud de los trabajadores en la vigilancia de COVID-19: un relato de experiencia
}

\begin{abstract}
RESUMO
Objetivo: descrever a experiência de docentes universitários frente às estratégias desenvolvidas na vigilância à saúde de colaboradores ao retorno das atividades laborais. Método: Relato de experiência desenvolvido por docentes de um Centro Universitário no Estado do Rio de Janeiro/ Brasil. Resultados: Entre os 56 colaboradores, 60,7\% são mulheres, 44,6\% se autodeclaram brancos, 41,1\% são solteiros e a idade variou entre 22 anos e 66, refletindo cinco idosos no grupo. Apenas três tiveram diagnóstico de COVID-19 antes do retorno ao trabalho e 26,8\% apontaram contato com pessoas diagnosticadas com a doença nos últimos 15 dias. Conclusões: As ações de vigilância e educação em saúde oportunizaram identificar problemas e fatores de risco, bem como articular o conhecimento científico para uma melhor prática assistencial. Reforça-se a necessidade de orientações de saúde bem como ampliar a discussão sobre estratégias no enfrentamento da pandemia, oportunizando espaços seguros aos trabalhadores no retorno de suas atividades laborais.
\end{abstract}

DESCRITORES: Infecções por Coronavirus; Pandemias; Saúde do Trabalhador.

\section{ABSTRACT}

Objective: to describe the experience of university professors regarding the strategies developed in health surveillance of employees when returning from work activities. Method: Experience report developed by professors at a University Center in the State of Rio de Janeiro / Brazil. Results: Among the 56 employees, 60.7\% are women, 44.6\% are self-declared white, $41.1 \%$ are single and their age varied between 22 years and 66 , reflecting five elderly people in the group. Only three were diagnosed with COVID-19 before returning to work and 26.8\% indicated contact with people diagnosed with the disease in the last 15 days. Conclusions: The health surveillance and education actions made it possible to identify problems and risk factors, as well as to articulate scientific knowledge for a better care practice. The need for health guidelines is reinforced, as well as broadening the discussion on strategies to face the pandemic, providing workers with safe spaces when returning from their work activities.

DESCRIPTORS: Coronavirus Infections; Pandemics; Occupational Health.

\section{RESUMEN}

Objetivo: describir la experiencia de profesores universitarios sobre las estrategias desarrolladas en la vigilancia de la salud de los empleados al regresar de las actividades laborales. Método: Informe de experiencia elaborado por profesores de un Centro Universitario del Estado de Rio de Janeiro / Brasil. Resultados: Entre los 56 empleados, el 60,7\% son mujeres, el 44,6\% se autodeclaran blancos, el $41,1 \%$ son solteros y su edad varió entre 22 años y 66 , reflejando cinco personas mayores en el grupo. Solo tres fueron diagnosticados con COVID-19 antes de regresar al trabajo y el 26.8\% indicó haber tenido contacto con personas diagnosticadas con la enfermedad en los últimos 15 días. Conclusiones: Las acciones de vigilancia y educación en salud permitieron identificar problemas y factores de riesgo, así como articular conocimientos científicos para una mejor práctica asistencial. Se refuerza la necesidad de contar con lineamientos de salud, además de ampliar la discusión sobre estrategias para enfrentar la pandemia, brindando espacios seguros para que los trabajadores regresen a sus actividades laborales.

DESCRIPTORES: Infecciones por Coronavirus; Pandemias; Salud Laboral.

RECEBIDO EM: 29/10/2020 APROVADO EM: 09/11/2020 


\section{Ana Cristina da Silva Oliveira}

Enfermeira. Coordenadora do Estágio Supervisionado do Curso de Graduação Anhanguera. Professora do Centro Universitário Anhanguera de Niterói, Rio de Janeiro, Brasil.

ORCID: 0000-0002-8414-2561

\section{Giuliana Fernandes e Silva}

Enfermeira. Doutora em Enfermagem. Professora do Centro Universitário Anhanguera de Niterói, Rio de Janeiro, Brasil. ORCID: 0000-0002-1130-2587

\section{INTRODUÇÃO}

A Organização Mundial da Saúde (OMS), em dezembro de 2019 notificou casos de pneumonia, com agente desconhecido, ocorridas na província de Wuhan, China. Sendo posteriormente confirmado um novo tipo de coronavírus, o SARS-CoV-2 causador da doença denominada Corona Virus Disease (COVID-19), a qual trata-se de uma afecção respiratória altamente contagiosa. Frente a este acontecimento, foram estabelecidas medidas de prevenção e controle, como a adoção do distanciamento social, de medidas de etiqueta respiratória, do uso da precaução padrão e das específicas de contágio respiratório e de contato. ${ }^{1}$

Os sintomas da COVID-19 progridem gradualmente, em média 5 dias de incubação. $\mathrm{O}$ período de aparecimento da doença até a morte pode ocorrer de 6 a 41 dias, numa média de 14 dias. Quanto aos sintomas, os mais comuns são febre, tosse e falta de ar, outros sintomas não específicos ou atípicos que podem ocorrer são dor de garganta, diarreia, anosmia ou hiposmia, ageusia, mialgia e cansaço ou fadiga.

O SARS-COV 2 pode ser transmitido através de gotículas respiratórias, expelido durante a fala, tosse ou espirros e pelo contato direto com a pessoa infectada ou por contato com objetos e superfícies contaminados. Essa transmissão, pode ainda, ocorrer pela aerossolização de substâncias corpóreas durante procedimentos que manejam as vias aéreas, como intubação, extubação, aspiração, ressuscitação cardiopulmonar, ventilação não invasiva e broncoscopia. $^{2}$

$\mathrm{O}$ enfrentamento da pandemia do novo coronavírus faz parte das funções essenciais da Saúde Pública por meio de ações voltadas para a população ou para grupos com maior risco de contaminação, como os profissionais de saúde. Entretanto, outras atividades de trabalho podem ter um papel importante na disseminação do vírus e, portanto, a análise de como se processam é determinante para a prevenção do adoecimento. ${ }^{3}$ A pouca visibilidade desse aspecto implica sua pouca valorização nas políticas públicas. O campo do trabalho como um todo deve ser considerado na estratégia de enfrentamento da pandemia.

No Brasil, o segundo óbito por coronavírus registrado foi o de uma empregada doméstica no Rio de Janeiro, cuja doença foi contraída no exercício do trabalho. ${ }^{4}$ Em Singapura, $68 \%$ dos 25 casos iniciais de contaminação comunitária foram atribuídos ao exercício profissional. ${ }^{5}$

Essas situações destacam que tanto o exercício das atividades laborais quanto as condições de trabalho são fontes potenciais de exposição ao vírus. Nesse sentido, a situação de trabalho constitui um ambiente de disseminação da doença, tornando fundamental compreender estratégias que possam contribuir no enfretamento da pandemia.

A preocupação em relação à reabertura das escolas e Universidades é um tema intersetorial e que precisa ser entendido como prioritário no contexto da pandemia. A crise sanitária mundial exacerbou iniquidades, ampliando ainda mais as disparidades educacionais, constituindo um agrave problema no enfrentamento da desigualdade. Trata-se de uma emergência sanitária que se transformou em uma crise humanitária com a perda de muitas vidas e a degradação da qualidade de vida de uma grande parte da população mundial. ${ }^{6}$

Esse contexto traz enormes desafios para a Saúde Coletiva e para a Saúde Pública. O primeiro desafio a ser enfrenta- do é o controle o mais breve possível da pandemia, o que se constrói seguindo-se rigorosamente critérios científicos. Entretanto, além dos desafios impostos pelo controle da pandemia, existem preocupações no enfrentamento de disputas políticas e econômicas.

Frente ao exposto, este relato foi construído seguindo a seguinte questão norteadora: Quais as ações e medidas de segurança instituídas para o retorno ao trabalho em um Centro Universitário? Para responder a questão, o estudo teve como objetivo descrever a experiência de docentes universitários frente às estratégias desenvolvidas na vigilância à saúde de colaboradores ao retorno das atividades laborais. Esse relato busca ainda fomentar uma discussão sobre a responsabilidade e conscientização das instituições na abordagem de estratégias de atenção à saúde de seus profissionais.

Cabe destacar que, segundo dados da pandemia por Covid-19 no Brasil indicam a existência de cenários epidemiológicos distintos não apenas entre os estados, mas também em municípios de um mesmo estado. O cenário geral é alarmante e a reabertura feita em picos epidêmicos ou em locais com pouco tempo de melhora geral do número de casos podem comprometer todo esforço empenhado ao longo dos meses de imposição de medidas não farmacológicas de distanciamento físico para deter a disseminação do vírus.

No entanto, mesmo dentro dos municípios vários relatos indicam uma distribuição desigual do vírus, com maior impacto em áreas mais vulnerabilizadas dos centros urbanos. ${ }^{6}$ Nesse sentido, qualquer debate sobre retorno de atividades deve levar em conta tal heterogeneidade de cenários epidemiológicos e os diferentes estágios da pandemia no país. 


\section{MÉTODO}

Trata-se de um relato da experiência de docentes de um Centro Universitário, os quais realizaram uma ação de vigilância e educação em saúde à profissionais que retornaram as atividades de trabalho. $\mathrm{O}$ retorno ocorreu após o isolamento de 5 meses que permaneceram em trabalho remoto e posteriormente à autorização $\mathrm{Mu}$ nicipal para retorno das atividades presenciais em um município do Estado do Rio de Janeiro/Brasil.

Cabe ressaltar que a atividade foi desenvolvida pelos docentes e acadêmicos do Curso de Graduação em Enfermagem. A Instituição possui um total de 327 colaboradores e o retorno às atividades presenciais foi uma liberação apenas para os profissionais técnicos administrativos, professores que atuam na clínica escola, porteiros e profissionais da limpeza que correspondem à 56 colaboradores. Como critérios de inclusão estabeleceu-se a participação voluntária nas ações de orientação em saúde, bem como o interesse em realizar o teste rápido para COVID-19. Foram excluídos os profissionais que não estavam aptos ao retorno das atividades de trabalho presenciais.

O Curso de Graduação em Enfermagem do Centro Universitário mantém um bom vínculo com os colaboradores, visto que constantemente realiza atividades de educação e promoção à saúde com os profissionais nos diferentes setores que compõem o Centro Universitário. Além disso, o Curso possui um Consultório de Enfermagem na Clínica Escola deste Centro, que constitui campo de estágio para discentes e docentes atuarem.

Este espaço, recentemente inaugurado, contribui para o acolhimento dos colaboradores nas campanhas de imunização da influenza e foi campo para consulta de enfermagem a estes trabalhadores que retornaram às atividades presenciais.

As ações de vigilância foram realizadas no período de setembro e outubro de 2020 , organizadas em três etapas: a primeira contemplou a busca de literatura confiável para fundamentar a proposta; organização da atividade, que constituiu uma ação prática de estágio supervisionado, com roteiro sobre as condições de saúde dos colaboradores, orientações expositivas dialogadas e, realização de teste rápido para COVID-19.

\section{As atividades}

desenvolvidas que

compõe a descrição

desse relato de

experiência foram

realizadas em três

etapas. A primeira

etapa consistiu-se

de uma busca livre

na literatura sobre

o COVID-19 e as

ações de controle

recomendadas pelos

órgãos nacionais $\mathrm{e}$

internacionais.

Todos os colaboradores que atuam na unidade, entre os quais, assistente administrativo, recepcionistas, professores e porteiros, foram convidados a participar. Este grupo de participantes teve um total de 56 pessoas. Após pactuação de agendamento, os docentes e acadêmicos estiveram em cada um dos setores para a realização das atividades presenciais, desenvolvidas por meio de exposição dialogada, com apontamentos sobre as principais dúvidas dos profissionais presentes, sobre o uso adequado da máscara e higienização das mãos. O roteiro de vigilância sobre questões de saúde dos colaboradores foi online, diminuindo o contato de manuseio de objetos entre as pessoas.

As ações realizadas tiveram uma repercussão positiva junto aos colaboradores e isto fez com que o Reitor do Centro Universitário solicitasse ao grupo a realização de uma atividade de capacitação para os porteiros, que serão multiplicadores na recepção das pessoas ao entrarem no Centro Universitário. Os docentes aceitaram mais este desafio e agendaram um encontro, em local adequado para o momento, que seguiu as recomendações do Ministério da Saúde e Organização Mundial de Saúde.

Não houve intervenção além das orientações de saúde elaboradas pelos docentes e acadêmicos. Durante as etapas, os aspectos éticos foram seguidos e preservou-se o anonimato dos participantes da ação, respeitando a Resolução do Conselho Nacional de Saúde 466/2012.

\section{RESULTADOS}

As atividades desenvolvidas que compõe a descrição desse relato de experiência foram realizadas em três etapas. A primeira etapa consistiu-se de uma busca livre na literatura sobre o COVID-19 e as ações de controle recomendadas pelos órgãos nacionais e internacionais. Foram levantados documentos no Word Health Organization, Agência Nacional de Vigilância Sanitária e Fundação Oswaldo Cruz.

Após o levantamento dos manuais e recomendações técnicas, foi realizado um diagnóstico situacional sobre o ambiente do Centro Universitário. Este documento descritivo trouxe as necessidades de mudanças estruturais que pudessem atender as normas estabelecidas pela Instituições municipais, estaduais e federais para o distanciamento social e segurança dos colaboradores. Após as mudanças o cronograma de retorno das atividades presencias ocorreu. 
A recepção dos colaboradores na Instituição aconteceu de maneira tranquila, previamente estes receberam informações sobre a necessidade do uso obrigatório das máscaras e higienização das mãos.

Em uma análise do perfil destes trabalhadores que retornaram à Unidade, dos 56 (100\%), 60,7\% são mulheres, compondo a maioria deste universo, $44,6 \%$ se autodeclaram brancos, $41,1 \%$ são solteiros e a idade variou entre 22 anos e 66, refletindo cinco idosos dentro grupo, como pode ser observado no gráfico a seguir:

Em relação a escolaridade, $62 \%$ possuem pós graduação, representação alto nível de compreensão, considerando que uma baixa escolaridade pode colaborar por reduzir sua compreensão sobre contextos de vulnerabilidade, dificultar o reconhecimento de situações de risco e problemas de saúde, comprometendo a capacidade de tomar decisões informadas sobre sua saúde.

Em relação ao local de moradia, a maioria dos colaboradores apontaram residir em outro município que não onde trabalham, o que demonstra a necessidade de deslocamento maior para Instituição. Sobre os hábitos de vida e saúde, apenas 7,1\% citaram o consumo de cigarro, $39,3 \%$ fazem o consumo de bebidas alcóolicas e $55,4 \%$ praticam atividade física. Sobre as

\section{Gráfico 1 Distribuição da idade dos colaboradores em um Centro Universitário} do Estado do Rio de Janeiro. Brasil, 2020.

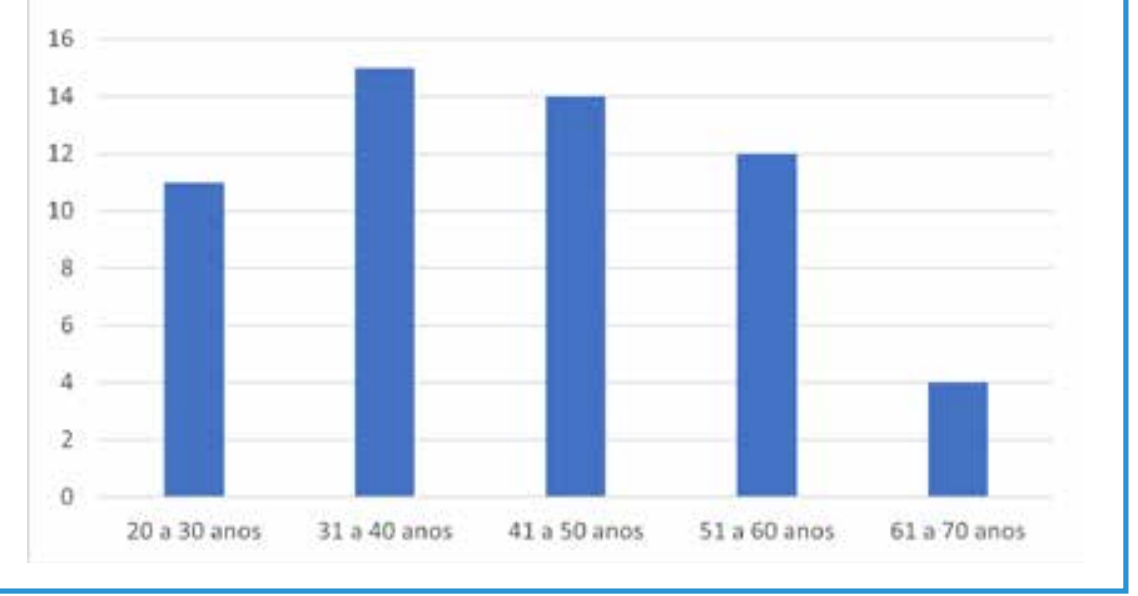

Fonte: Dados da pesquisa.

Gráfico 2 - Distribuição dos colaboradores que foram diagnosticados pelo COVID-19 antes do retorno às atividades de trabalho em um Centro Universitário do Estado do Rio de Janeiro. Brasil, 2020.

Teve diagnóstico da doença causada pelo Coronavirus (COVID-19) nos últimos 30 dias? So respentas

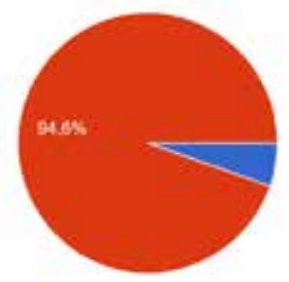

condições de sono e repouso a maioria dos colaboradores apontaram ter em médica 8 horas de sono. Uma parcela afirmou o diagnóstico de doenças crônicas como hipertensão e diabetes, representando $32,1 \%$ e $17,9 \%$ respectivamente.

Ao serem questionados sobre o contexto da pandemia e se já tiveram o diagnóstico de COVID-19 nos últimos 30 dias, apenas 3 colaboradores afirmaram que sim, como pode ser observado no gráfico 3 .

Ainda que em número reduzido no diagnóstico anterior para COVID-19, $26,8 \%$ dos colaboradores apontaram que tiveram contato com pessoas diagnosticadas com a doença nos últimos 15 dias. Em relação ao questionamento sobre sintomas de febre, tosse, dor de garganta e falta de ar nos últimos 15 dias, 91,1\% afirmaram que não apresentaram nenhum desses sintomas.

Uma preocupação também destacada e questionada antes do retorno dos trabalhadores foi em relação às gestantes. Nesse sentido, as mulheres foram questionadas sobre a possibilidade de gravidez. E todas $(100 \%)$ as colaboradoras responderam que não.

\section{DISCUSSÃO}

É indiscutível a importância da educação, não apenas para as crianças e jovens, mas para toda a sociedade. A Lei de Diretrizes e Bases da Educação (Lei 9.394/1996) ${ }^{8}$, em seu Art. $1^{\circ}$, define que a educação abrange os processos formativos que se desenvolvem na vida familiar, na convivência humana, no trabalho, nas instituições de ensino e pesquisa, nos movimentos sociais e organizações da sociedade civil e nas manifestações culturais.

A preocupação e as repercussões sobre as questôes educacionais permanecem na maior parte dos países, das diferentes regiões do mundo. Os sistemas de ensino fecharam as escolas em respeito ao princípio da precaução sanitária diante da emergência sanitária que acomete a humanidade. No Brasil, aproximadamente 44 milhões de estudantes ficaram sem aulas presenciais9, e em cada sistema de ensino foi necessário repensar práticas de ensino e 


\section{artigo}

Oliveira, A.C.S.; Fernandes e Silva, G.

Atenção à saúde do trabalhador na vigilância ao COVID-19: um relato de experiência

aprendizagem para garantir, mesmo remotamente, os 200 dias letivos. Essa realidade compóe o contexto do ensino superior de educação.

A gravidade sanitária global tem como fundamento a compreensão que a doença se propaga por transmissão respiratória e é de alta transmissibilidade. Nesse sentido, as diferentes nações continuam em debate as possibilidades de como enfrentar com esta ameaça, para a qual ainda não existem, até o momento, terapêuticas específicas que interrompam a multiplicação do vírus, uma vez tendo ocorrido a infeção, ou vacinas que impeçam a ocorrência de novas infeções.

Somando a isto, e considerando que ainda não se conhece as especificidades da história natural da doença, é indispensável acompanhar continuamente as publicações dos órgãos oficiais para adequação das recomendações de precaução, diante de novas descobertas sobre o comportamento da doença. ${ }^{10}$

Entre as ações preventivas e de combate ao COVID-19, a proteção aos idosos é estratégia prioritária, tendo em vista que eles constituem grupo com maior risco de complicações e de morte pela COVID-19. As pessoas com mais de 60 anos de idade, por serem as mais vulneráveis, devem permanecer em casa sempre que possível, restringir seus deslocamentos para realização de atividades estritamente necessárias, evitar o uso de meios de transporte coletivo, e não frequentar locais com aglomerações. ${ }^{11}$

Na primeira semana de retorno, ocorreram as orientações presenciais em cada setor dos colaboradores e a exposição dialogada com orientações sobre conduta de distanciamento, higienização das mãos, uso correto das máscaras, bem como a correta limpeza e manuseio. Os colaboradores foram ainda convidados para uma consulta de enfermagem na clínica escola, foi apresentado o calendário com as campanhas de imunização de influenza e sarampo com convite à sua participação também nessas atividades. Foi ofertado teste rápido para vigilância frente a exposição dos colaboradores que apresentaram sinais e sintomas ou tiveram contato com pessoas diagnosticadas pelo COVID-19. Entre os 10 colaboradores que realizaram o teste rápido no consultório de enferma- gem todos tiveram resultado negativo.

Antes da entrada dos colaboradores diariamente é verificado a temperatura corporal e disponibilizado álcool gel a $70 \%$, bem como a orientação para melhor eficiência do resultado sobre espalhar o produto em toda a superfície das mãos e friccionar por 20 segundos.

\section{CONCLUSÃO}

As ações de vigilância e educação em saúde oportunizaram identificar problemas e fatores de risco, bem como articular o conhecimento científico para uma melhor prática assistencial. É possível articular o ensino e teoria contribuindo para a ampliação da qualificação profissional e a segurança dos profissionais envolvidos no combate a pandemia.

Neste relato os autores que compõe esse estudo contribuíram na avaliação do cenário Institucional para planejamento do retorno das atividades presenciais, na participação da etapa de orientação com os colaboradores e levantamento sobre as condições de saúde, na redação e revisão crítica do presente manuscrito.

\section{REFERÊNCIAS}

1. World Health Organization. (2019/2020). Coronavirus disease (COVID-19) pandemic; [citado em 2020 ste 07].

2. Chan JF, Yuan S, Kok KH, To KK, Chu H, Yang J. A familial cluster of pneumonia associated with the 2019 novel coronavirus indicating person-to-person transmission: a study of a family cluster. Lancet. 2020;395(10223):514-523. doi: 10.1016/S0140-6736(20)30154-9. COVED Anaesthetic Induction. 2020.

3. Baker MG, Peckham TK, Seixas NS. Estimating the burden of United States workers exposed to infection or disease: a key factor in containing risk of COVID-19 infection. The preprint server for health sciences. 2020.

4. BBC News Brasil [Internet]. São Paulo: Vinícius Lemos; 2020 [citado em 5 abr 2020]. Ministério Público do Trabalho analisa morte de doméstica no RJ após patroa ter coronavírus.

5. Koh D. Occupational risks for COVID-19 infection. Occup Med. 2020 [citado em 4 abr 2020];70(1):3-5.

6. Gutiérrez, Adriana Coser et al. Contribuições para o retorno às atividades escolares presenciais no contexto da pandemia Covid-19. Rio de Janeiro: Fiocruz, 2020. 86 p.
7. Brasil. Ministério da Saúde. Conselho Nacional de Saúde. Resolução n. 466, de 12 de dezembro de 2012. Aprova diretrizes e normas regulamentadoras de pesquisas envolvendo seres humanos. Brasília, Diário Oficial da União, 12 dez. 2012.

8. Brasil. Presidência da República. Casa Civil. Subchefia para Assuntos Jurídicos. Fernando Henrique Cardoso. Lei n 9.394, de 20 de dezembro de 1996. Diretrizes e bases da educação nacional. Brasília, 20 de dezembro de 1996; 175² da Independência e $108^{\circ}$ da República.

9. Organização Mundial da Saúde. Fundo das Nações Unidas para a Infância. Considerações para medidas de saúde pública relacionadas às escolas no contexto da COVID-19. Anexo às considerações para adaptar as medidas sociais e de saúde pública no contexto da COVID-19. 14 de setembro de 2020.

10. World Health Organization (WHO). Coronavírus Disease (COVID-19) pandemic [Internet]. 2020.

11. Pires, Luiza Nassif, Laura Carvalho, and Laura de Lima XAVIER. "COVID-19 e desigualdade: a distribuição dos fatores de risco no Brasil." Research Gate. USP (2020). 